\title{
Hearing, Cognition, and Healthy Aging: Social and Public Health Implications of the Links between Age-Related Declines in Hearing and Cognition
}

\author{
M. Kathleen Pichora-Fuller, Ph.D., 1,2,3 \\ Paul Mick, MD, MPH, FRCSC, ${ }^{4,5}$ and Marilyn Reed, M.Sc. ${ }^{6}$
}

Sensory input provides the signals used by the brain when listeners understand speech and participate in social activities with other people in a range of everyday situations. When sensory inputs are diminished, there can be short-term consequences to brain functioning, and long-term deprivation can affect brain neuroplasticity. Indeed, the association between hearing loss and cognitive declines in older adults is supported by experimental and epidemiologic evidence, although the causal mechanisms remain unknown. These interactions of auditory and cognitive aging play out in the challenges confronted by people with agerelated hearing problems when understanding speech and engaging in social interactions. In the present article, we use the World Health Organization's International Classification of Functioning, Disability and Health and the Selective Optimization with Compensation models to highlight the importance of adopting a healthy aging perspective that focuses on facilitating active social participation by older adults. First, we examine epidemiologic evidence linking ARHL to cognitive declines and other health issues. Next, we examine how social factors influence and are influenced by auditory and cognitive aging and if they may provide a possible explanation for the association between ARHL and cognitive decline. Finally, we outline how audiologists could reposition hearing health care within the broader context of healthy aging.

${ }^{1}$ Department of Psychology, University of Toronto, Toronto, Ontario, Canada; ${ }^{2}$ Toronto Rehabilitation Institute, University Health Network, Toronto, Ontario, Canada; ${ }^{3}$ Rotman Research Institute, Toronto, Ontario, Canada; ${ }^{4}$ Department of Surgery, University of British Columbia, Vancouver, British Columbia, Canada; ${ }^{5}$ Kelowna General Hospital, Kelowna, British Columbia, Canada; and; ${ }^{6}$ Baycrest Health Sciences, Toronto, Ontario, Canada. Address for correspondence: M. Kathleen PichoraFuller, Ph.D., Department of Psychology, University of
Toronto, 3359 Mississauga Rd N., Mississauga, ON, Canada L5L 1C6 (e-mail: k.pichora.fuller@utoronto.ca). Cognition and the Aging Auditory System; Guest Editor, Lindsey E. Jorgensen, Au.D., Ph.D. Semin Hear 2015;36:122-139. Copyright (C) 2015 by Thieme Medical Publishers, Inc., 333 Seventh Avenue, New York, NY 10001, USA. Tel: +1(212) 584-4662. DOI: http://dx.doi.org/10.1055/s-0035-1555116. ISSN 0734-0451. 
KEYWORDS: Social isolation, social support, healthy aging, agerelated hearing loss (ARHL), cognitive aging

Learning Outcomes: As a result of this activity, the participant will be able to (1) discuss the evidence regarding the associations between age-related hearing loss ( $A R H L$ ) and other age-related health issues, and (2) describe how social factors influence and are influenced by ARHL to guide new approaches to audiologic practice.

\section{HEALTH, HEALTHY AGING, AND THE IMPORTANCE OF SOCIAL FUNCTIONING}

All too often, old age is associated with difficulties such as multiple health problems, including declines in auditory and cognitive abilities, and social isolation. Sensory input provides the signals used by the brain when listeners understand speech, enjoy music, detect warning signals, react to environmental sounds, and participate in social activities with other people in a range of everyday situations. When sensory inputs are diminished, there can be short-term consequences to brain functioning, and long-term deprivation can affect brain neuroplasticity. Importantly, the interactions of auditory and cognitive aging play out in everyday life as people with age-related hearing problems communicate, participate in social activities, and maintain social roles and relationships.

In the present article, we consider how agerelated sensory, cognitive, and social functioning may be interrelated and the implications of such interrelationships for rehabilitative audiology. In particular, we use the World Health Organization's International Classification of Functioning, Disability and Health (WHO ICF) and the Selective Optimization with Compensation (SOC) model of Baltes and Baltes to highlight the importance of adopting a healthy aging perspective that focuses on facilitating active social participation by older adults. 1,2

The WHO ICF provides a familiar framework that has been used by audiologists. ${ }^{3}$ Two key features of the WHO ICF are that functioning is conceptualized with bidirectional influences across a trio of levels (impairment, activity, and participation) spanning biological to social factors and that functioning occurs in context and can be modulated by personal and environmental factors. All components of the system are linked to each other such that change in one will yield changes in others. Importantly, modifying contextual factors by removing barriers and/or enhancing supports can facilitate healthy functioning for an individual. Ideally, healthy functioning would result if personal resources and supportive physical and social environments were optimized to offset the potentially negative consequences of biological impairments. From an ecological perspective, an optimized person-context fit would promote healthy adaptation, ${ }^{4}$ enabling the person to cope successfully and achieve their goals without stress.

According to the SOC model, "successful" aging involves modifying the balance between losses and gains such that, as older adults continue to develop in their later life, it remains possible to have a positive balance. The SOC model assumes that as adults age there is intraindividual plasticity and interindividual variability (i.e., all individuals can change with age, but they may differ in how they change). The model describes three key processes involved in successful aging: (1) selection and prioritization of goals to be achieved with limited resources; (2) optimization of how limited resources are deployed to achieve selected goals (e.g., developing new skills can improve the efficiency of resource use); (3) compensation by drawing on relatively intact abilities (or using assistive technologies) to offset declining abilities so that selected goals can be achieved in new ways. The SOC model can be applied in rehabilitation to understand how older adults cope successfully with declines and various disabilities (e.g., recovery from stroke). ${ }^{5}$ The model can also be used to understand how younger and middle-aged people can prevent 
declines and prepare for successful aging by engaging proactively in health-promoting lifestyles. ${ }^{6}$

Health has been defined as a state of complete physical, mental, and social wellbeing and not merely the absence of disease or infirmity, ${ }^{7}$ but from the perspective of health promotion, health has been redefined as the capacity of people to adapt to, respond to, or control life's challenges and changes. ${ }^{8}$ Importantly, hearing health needs to be thought of as part of this capacity for people to live their lives optimally. We are poised to reinvent hearing health care for older adults by adopting a healthy aging approach.

\section{LINKS BETWEEN HEARING LOSS, COGNITIVE DECLINE, AND THE HEALTH OF OLDER ADULTS}

The population is aging rapidly; a historically unprecedented large proportion of the population is becoming seniors as those in the "baby boomer" generation turn 65 years old. Another reason is that longevity has increased, with more people living to older ages, including many who are centenarians. ${ }^{9-11}$ Indeed, the most rapid reductions in mortality are occurring in the "oldest old" age group of octogenarians and nonagenarians. ${ }^{12}$ Accordingly, in the coming years, audiologists should expect to see more people who are living to older ages and whose needs differ from those of younger adults.

In general, as the population ages, the burden of disease and mortality is shifting with increases in chronic, noncommunicable, and geriatric illnesses; specifically, a recent study of projected global disease burden, using estimates based on trends in demographic and socioeconomic factors, suggested that dementias and adult-onset hearing loss will be among the top 10 causes of total disability in highincome countries by the year $2030 .^{13}$ Not surprisingly, given the increasing prevalence of hearing loss, dementia, and other chronic health conditions, it is becoming more common for older adults to have multiple comorbidities. Indeed, there is growing awareness that hearing loss must be factored into social policies to promote healthy aging and programs to provide a wide range of health services to older adults. ${ }^{14}$
Nonauditory age-related health conditions may influence hearing loss and hearing health care. For example, hearing loss has been linked to other major chronic health conditions that may be risk factors for hearing loss, including diabetes ${ }^{15}$ cardiovascular disease, ${ }^{16}$ and hypertension. ${ }^{17}$ Furthermore, hearing rehabilitation, including use of hearing aids, may be complicated by nonauditory age-related conditions, such as visual impairment or loss of manual dexterity due to arthritis. ${ }^{18-20}$ Conversely, hearing loss and hearing health care may influence other age-related health conditions. Clearly, the association between hearing loss and incident dementia has become a concern. However, like many geriatric health conditions, dementia rarely has a single cause; although various types of dementia have been identified, their etiologies are not yet well understood and likely involve a complex interaction of many genetic, lifestyle, and environmental factors. ${ }^{21}$ Furthermore, hearing loss is associated with and may precede a broad range of other age-related mental and physical health issues besides dementia, including depression, ${ }^{22}$ difficulties walking, ${ }^{23}$ falls, ${ }^{24,25}$ poorer physical functioning and increased risk in women of incident nursing care requirements, ${ }^{26}$ frailty,${ }^{27}$ and even mortality. ${ }^{28-32}$ Similar to hearing loss, dementia and cognitive dysfunction also contribute to falls, ${ }^{33}$ length of stay in hospital, ${ }^{34}$ more intensive nursing care, ${ }^{35}$ and poorer recovery after surgery, ${ }^{36}$ and hospital stays and surgery may increase rates of cognitive declines in older individuals with and without dementia on admission. ${ }^{37}$ In addition, provocative findings indicate that hearing loss may undermine the quality and costs of health care, and that hospital costs for patients with dementia are higher compared to costs for peers without dementia, ${ }^{38,39}$ even in analyses that control for severity of medical illness, functional impairment, and other potentially confounding variables. Thus, the implications of hearing loss in older adults, especially in those who have or may develop dementia, extend to many aspects of health and health care.

Of course, many older people with hearing loss are cognitively normal, and not all people with dementia have hearing loss. Nevertheless, the increasingly common co-occurrence of 
declines in sensory loss and cognitive loss as people get older does not seem to be merely a result of increasing prevalence in unrelated conditions, but rather that these conditions are interrelated. ${ }^{40}$ Convincing evidence has emerged suggesting that cognitive loss is more prevalent or may progress more quickly in people with hearing loss than in their peers with good hearing. Audiologists will need to be prepared to help an increasing number of older adults who are living with hearing loss in combination with other chronic health issues, but especially those who have both hearing loss and dementia. ${ }^{41}$

The strongest epidemiologic evidence linking pure tone hearing loss to accelerated cognitive decline and dementia comes from two large, population-based cohort studies with long follow-up periods. The first study included a cohort of 639 dementia-free older individuals who underwent audiometric pure tone threshold testing in the early 1990s. ${ }^{42}$ The participants returned for follow-up every 2 years with a median follow up of over 11 years. Whether or not the time to incident all-cause dementia depended on the severity of hearing loss was investigated using Cox proportional hazards regression models adjusted for age, sex, race, education, diabetes, smoking, and hypertension. Strikingly, the risk of incident dementia increased by 1.27 times per $10-\mathrm{dB}$ increase in hearing thresholds. Relative to people with normal hearing, the incidence of all-cause dementia was 1.89 times higher in people with mild hearing loss, 3 times higher in people with moderate hearing loss, and 4.94 times higher in people with severe hearing loss. To put the effect size into context, the authors calculated that the cognitive reduction associated with a $25-\mathrm{dB}$ loss in hearing was equivalent to the reduction associated with an increase of 7 years in age. Similar results were found in the second study of nearly 2,000 people in the Health ABC cohort who were 70 to 79 years old. ${ }^{43}$ In that study, participants from Pittsburgh and Memphis with mild to severe hearing loss had faster rates of cognitive decline compared with normal hearing participants, even after adjusting for possible confounders due to demographic or health factors. Furthermore, at least two earlier studies conducted by other researchers have shown faster rates of cognitive declines among patients who already had dementia with hearing loss compared with those with normal hearing. ${ }^{44,45}$ In addition to associations between pure tone hearing loss and dementia, other studies have also demonstrated that performance on tests of central auditory processing (e.g., dichotic tests of speech in noise) are associated with cognitive status and incident dementia. ${ }^{46-49}$ Taken together, these studies establish that there is a link between auditory and cognitive aging, but further research is required to determine why there is a link or if the link can be modified by intervention. The explanations for the link may be based on biological, cognitive, and/or social mechanisms. In the present article, the biological and cognitive mechanisms are mentioned briefly, but there is greater focus is on the possible social mechanisms that may be associated with the link between auditory and cognitive aging.

\section{Possible Biological Mechanisms}

A common neurodegenerative pathology could conceivably lead to both hearing loss and dementia. The pathognomonic $\beta$-amyloid plaques, neurofibrillary tangles, and neuronal atrophy of Alzheimer disease have been observed in the peripheral visual neural and olfactory sensory systems at autopsy, and reduced smell is an early clinical symptom of the disease; however, Alzheimer pathology, although affecting the central auditory system, ${ }^{50}$ has not been demonstrated in peripheral structures like the cochlea or cochlear nerve. ${ }^{40}$ Other possible biological risk factors common to both hearing loss and dementia could be a variety of genetic, inflammatory, or immunologic and/or other health conditions (e.g., cardiovascular disease, hypertension, diabetes, stress) that are often controlled in epidemiologic studies as possible confounders. ${ }^{43,51}$

\section{Possible Cognitive Mechanisms}

Cognitive mechanisms may contribute to the link between hearing and dementia. Evidence for cognitive mechanisms comes from research on age-related changes in brain structure, 
functional brain networks, and behavioral performance.

A link between hearing loss and changes in brain structure is suggested by recent radiographic evidence from a brain imaging study of participants in the Baltimore Longitudinal Study of Aging. ${ }^{52}$ Among a cohort of 126 dementia-free individuals, the mean rate of brain volume reduction over a 6.4-year follow-up was greater among participants with hearing loss. The size of this effect was approximately equivalent to the average difference seen between people with normal cognition and people with mild cognitive impairment. In particular, hearing loss was related to greater changes in the temporal lobe structures, which are important for spoken language processing, semantic memory, and sensory integration, and atrophy in the medial temporal lobe is found in the early stages of Alzheimer's disease. ${ }^{53-58}$

Beyond changes in brain structures, it is even more important to understand more about changes in brain function and associated behaviors. Notably, in addition to biological changes in the brain and reduced performance on behavioral tests of memory, a necessary condition of dementia diagnosis is loss of ability to function independently in everyday life. ${ }^{59,60}$ Building on what has been learned about agerelated changes in functional brain networks, ${ }^{61}$ further research using functional brain measures is needed to determine how sensory-cognitive brain networks may change over time and how these changes relate to functioning in different everyday communication situations. ${ }^{62}$ Two main themes that have emerged in research on the cognitive neuroscience of aging are that there are individual differences in cognitive reserve and that there is cognitive compensation such that patterns of brain activation for a given individual vary depending on the cognitive load demanded by a task.

The concept of cognitive reserve refers to individual differences in cognition that seem to moderate the extent to which dementia pathology manifests in symptoms of disease. ${ }^{63}$ People with greater cognitive reserve are thought to have neural networks that are less susceptible to disruption such that they can compensate better for pathologic changes in the brain and thereby maintain functioning in everyday life. ${ }^{64}$ At a certain point, however, even individuals who have greater cognitive or brain reserves can no longer compensate for neural degeneration and the clinical manifestation of disease becomes apparent, even though symptoms have been delayed relative to others who have less reserve. Cognitive reserve is thought to be greater for those who are more educated, have higher IQs, work in occupations or engage in activities with rich opportunities for mental and social engagement, and adopt healthy lifestyles in terms of diet and physical activity. ${ }^{65,66}$ Thus, there may be interindividual differences insofar as older adults may begin the process of adjusting to hearing loss having accumulated more or less cognitive reserve over their lifetimes. In the long term, if hearing loss compromises an individual's ongoing lifestyle choices, resulting in reduced engagement in physical, mental, and social activity, then the maintenance of the person's cognitive reserve may be compromised. In this way, over many years, hearing loss may accelerate the depletion of cognitive reserve as dementia progresses. For a given person at a given point in time, there are also intraindividual differences in how brain networks are activated depending on the cognitive load demanded by various tasks. In studies of brain function, increasing brain activation as the cognitive load demanded by a task increases has been interpreted as evidence of cognitive compensation. $^{61}$

The notions of cognitive reserve and cognitive compensation are compatible with behavioral findings concerning interindividual and intraindividual differences in listening performance. ${ }^{67,68}$ The cognitive demands encountered by a listener performing tasks in everyday life vary depending on a variety of interacting factors related to the characteristics of the listener and the signal(s) produced by one or more sources in a context. ${ }^{69}$ Listener characteristics, including cognitive reserve, contribute to interindividual differences in performance. Individuals of the same age can differ in their auditory and cognitive processing abilities, and in their linguistic and world knowledge; however, in general, processing abilities decline whereas knowledge increases or is maintained as adults get older. ${ }^{70}$ Finally, consistent with the SOC model, listeners may differ in their goals 
or selection of priorities for allocating cognitive resources, especially when there are multiple competing tasks. These listener characteristics interact with signal and context factors that contribute to situation-specific intraindividual differences in performance. In the terms of the SOC model, optimization could reduce and/or compensation could offset-increased cognitive load. The signal properties affecting the cognitive load demanded in a specific listening situation may include not only the acoustic (with or without optimization by the use of listening technologies) and the linguistic properties of a target speech signal, but also the properties of energetic and informational maskers, and converging or competing information from other sensory modalities. In addition, the cognitive load of a listening task will depend on many aspects of the context that may facilitate the use of semantic, social, and interpersonal knowledge and expectancies to interpret incoming signals.

In general, congruent or supportive contexts make the task easier and lessen cognitive load, and incongruent contexts make the task more difficult and increase cognitive load. Even if the acoustical conditions are the same, increased cognitive load (e.g., by increasing task demands) causes listeners to rely more on lexical knowledge and less on phonetic detail. ${ }^{71}$ Notably, younger adults rely relatively more on bottom-up processing of signal cues, whereas older adults rely relatively more on top-down processing of context cues. ${ }^{72}$ In effect, compared with younger listeners, older listeners may be chronically operating with more cognitive load and more frequently engaging compensatory patterns of brain activation. ${ }^{73}$ Over many decades, the compensatory shift in the use of different types of information during everyday listening may accompany permanent changes in patterns of activation in brain networks, such as changes in hemispheric asymmetry or shifts to more frontal lobe activation. $^{74,75}$ In addition, converging evidence suggests that the hippocampus is involved not only in memory but also in associative memory or the binding of information about items and contexts during the perception of complex stimuli. ${ }^{76,77}$ Experimental studies demonstrated age-related declines in item-item and item-context associative memory, with diminished ability to compensate by using context when information is encoded and with disruptions of auditory associations that are temporally defined. ${ }^{78,79}$ Insofar as those with age-related hearing loss (ARHL) may habitually experience even greater cognitive loads in typical listening situations, which might accelerate changes in brain networks, it is possible that they could show sooner or faster cognitive declines than peers with better hearing.

\section{HOW SOCIAL FACTORS INFLUENCE AND ARE INFLUENCED BY AUDITORY AND COGNITIVE AGING}

Social factors affect many aspects of health, including how people live with age-related auditory and cognitive declines; conversely, health and age-related auditory and cognitive declines affect social interactions and quality of life. The connections between auditory, cognitive, and social factors are illustrated by the comment of a doctor who summed up his experience with hearing loss as follows: "It affected me meeting girls and having girlfriends. Being made fun of for not hearing things, where people were making light of it. It hurt, but you'd never admit to it. People would say, 'You can hear, you just didn't pay attention.' And that was partly accurate. I stopped paying attention because I couldn't hear." ${ }^{80}$ How successfully an older adult selects, optimizes, and compensates in everyday life may depend on several relevant social factors, including stigma, self-efficacy, social support, social networks, and participation in social activities.

\section{Stigma, Stereotypes, and Self- Perceptions}

Stigma involves the (self-)identification of a person as having a characteristic that is devalued in a social context. ${ }^{81}$ Negative stereotypes of aging, as well as negative self-perceptions, may affect the health of older adults and how they function in everyday activities, such as communication and social interaction, which depend 
on both hearing and memory. ${ }^{82-84}$ Notably, memory and hearing are two domains in which older people are often negatively stereotyped. ${ }^{85-90}$ Age-related declines in memory and hearing may be exacerbated when older adults fall prey to negative stereotypes of aging, and negative views of aging may be one reason why older people's self-perceptions of ability do not always accurately reflect their actual function. ${ }^{91,92}$ The stigma associated with hearing loss is entangled with ageism, ${ }^{93}$ and perceptions of stigmatization can fuel the denial of hearing problems and nonadherence to rehabilitative treatments. ${ }^{94,95}$ The perception of stigma seems to differ between men and women, to vary with age, and to be associated more with hearing loss than with hearing-aid use. ${ }^{96}$ Importantly, age per se is not correlated with negative views of aging, ${ }^{97}$ and responses to stigma can vary depending on context such that some individuals are vulnerable while others are resilient to stigma. ${ }^{81}$ Thus, there is potential to tailor interventions according to the individual's responses to stigma.

\section{Self-Efficacy}

Self-efficacy refers to domain-specific "beliefs in one's capabilities to organize and execute the courses of action required to produce given attainments." 98(p.3) In general, individuals with high self-efficacy put forth greater effort in achieving a behavior, persevere when difficulties arise or failures occur, have self-aiding thoughts for achieving the behavior, and cope better with emotional, social, and environmental demands surrounding the behavior. ${ }^{98} \mathrm{Nu}-$ merous studies have demonstrated that domain-specific self-efficacy plays an important role in the successful management of a various chronic health conditions; for example, patients with high self-efficacy for managing diabetes have more positive outcomes, higher healthrelated quality of life, increased compliance with treatment recommendations, and better long-term maintenance of the modified behavior compared with patients with low self-efficacy. ${ }^{98-100}$ Thus, it seems that sufficient selfefficacy is critical if older adults are to seek help, take action, and modify and maintain the behavior changes required for successfully adaptation to ARHL. Importantly, audiologists could use techniques to increase the self-efficacy of older adults at various stages of the rehabilitative process. ${ }^{101}$

\section{Social Support}

Social support refers to the perceived quality, rather than the quantity, of relationships providing emotional or affective support (e.g., empathy), instrumental support (e.g., financial aid), and/or informational support (e.g., advice). ${ }^{102,103}$ Social support can have a powerful effect on outcomes for various health conditions by promoting the use of effective coping strategies and counteracting negative interpretations of adverse events. ${ }^{104,105}$ The importance of social support is demonstrated in the role played by significant others in hearing rehabilitation and by caregivers in dementia care. ${ }^{106}$ Significant others can act as a source of motivation and support for those using hearing aids, ${ }^{107,108}$ by encouraging the person who is hard-of-hearing to pursue and adhere to treatment, ${ }^{109,110}$ by acting as a facilitator for communication, and by providing information and instruction on the proper use and operation of hearing aids ${ }^{111-113}$; however, the negative attitudes of significant others may contribute to delaying help-seeking or rejecting treatment. ${ }^{114,115}$ The availability of the social support seems to differentiate successful from unsuccessful and satisfied from unsatisfied hearing aid users. ${ }^{116,117}$ Furthermore, social support is a strong predictor of adjustment to the psychological distress associated with hearing loss. ${ }^{118}$

Social support provided by significant others and caregivers may be beneficial to the person who has the impairment(s), but unfortunately, providing social support may strain relationships, increase stress, and compromise the health and quality of life of those who provide the support. Hearing loss affects not only the person who has hearing loss but also significant others, ${ }^{119-130}$ reducing their physical, psychological, and social well-being. In particular, third-party disability manifests in wide-ranging effects on the spouses of persons with hearing impairment, ${ }^{131}$ including communication difficulties, emotional sequelae, and effects on relationships and everyday 
activities. ${ }^{127,129}$ Similarly, the well-known burden of caregiving for an individual with dementia can result in changes in caregivers' own physical health, mental health, financial resources, and social participation. ${ }^{132,133}$ Dementia can result in difficulties with language and cognition, ${ }^{134,135}$ and hearing loss in this population can also lead to communication breakdowns. Importantly, breakdowns in communication increase caregiver burden and have been identified as one of the most distressing problems for caregivers of people with dementia. ${ }^{136-139}$ For example, many of the behavioral symptoms of $\mathrm{AD}$ and other dementias, such as frequent requests for repetition and difficulty following conversations, can lead to withdrawal from social situations and increased feelings of caregiver burden. The combination of declines in hearing and cognition may be overwhelming for caregivers, ${ }^{41}$ but audiologic rehabilitation of older adults with cognitive impairment and their significant others may help alleviate burden, increasing the efficiency of home care and delaying the client's move to institutional care. ${ }^{140}$

\section{Social Networks}

Significant others and caregivers are the core of an older person's social network. Indeed, as people age, their socioemotional priorities shift toward a focus on emotional regulation and having fewer, high-quality close relationships and away from a focus on knowledge acquisition and having larger social networks. ${ }^{141} \mathrm{Im}^{-}$ portantly, maintaining social connections is critical to healthy aging. Indeed, social isolation and loneliness are particularly common in older adults and increase their risks of mortality, mental and physical health issues, disabilities, and difficulty in making life-course transitions. ${ }^{142,143}$ Stronger social networks may reduce mortality, cardiovascular disease, depression, and anxiety, ${ }^{144-147}$ with the risk of mortality associated with social isolation being as great as that of other notorious clinical risk factors such as cigarette smoking and hypertension. ${ }^{148,149}$ Hearing loss in cognitively normal older adults has been related to reduced quality of life and increased social isolation and emotional distress, ${ }^{150}$ as well as reductions in physical capabilities and instrumental activities of daily living, such as managing medication. ${ }^{151}$ A recent population-based study conducted using nationally representative data for the United States confirmed that older people with hearing loss, especially women, had smaller social networks compared with people with normal hearing. ${ }^{152}$ Isolation may increase the risks of dementia onset and progression. Epidemiologic studies indicate that weaker social networks, reduced social support and loneliness increase the risk of incident dementia among those who are initially free of the disease, ${ }^{153,154}$ after controlling for potentially confounding variables. Again, age-related declines in hearing and cognition both increase risk of social isolation and in combination the risk is likely to be even greater. Preventing social isolation must be a target for audiologic rehabilitation designed to promote healthy aging.

\section{PARTICIPATION IN SOCIAL ACTIVITIES}

Beyond merely preventing social isolation, effective selection, optimization, and compensation would enable a person who is aging successfully to participate actively in enriching activities in everyday life. In models based on population data, there are significant paths from age to hearing to intelligence to participation in activities of daily living. ${ }^{155}$ In samples of people with hearing impairment (or vision impairment), relationships have been found between cognition and everyday functioning. ${ }^{156}$ Again, there are reciprocal issues insofar as not only do auditory and cognitive declines compromise active participation in everyday life, but reduced opportunities for social participation may accelerate further declines. Animal studies showed that social and sensory stimulation can strengthen the structure and function of the central nervous system at the cellular and molecular levels; for example, compared with controls isolated in sensory-deprived conditions, rats randomized to live among their peers in cages containing abundant sensory stimuli had lower concentrations of inflammatory cytokines and higher levels of protective neurotrophic factors in the hippocampus, with greater numbers of synapses per dendrite, larger neurons, 
and greater neurogenesis, as well as better spatial memory and learning behaviors. ${ }^{157} \mathrm{Sim}$ ilar molecular and cellular changes have been observed in animals exposed to greater levels of physical activity ${ }^{158}$ or reduced caloric intake, ${ }^{159}$ and these changes may mediate a path between healthy lifestyles and cognitive resilience. Of many studies conducted in humans, one of the most intriguing evaluated the Experience Corps, ${ }^{160}$ a social intervention in which at-risk older adults are trained and work as volunteers with children in classrooms; compelling evidence suggests that increasing meaningful social participation for the volunteers resulted in numerous positive outcomes, including improved physical performance (walking speed), improved cognitive performance (memory), and increased size of social networks. Furthermore, functional brain imaging provided evidence of intervention-specific increases in brain activity in the left prefrontal cortex and anterior cingulate cortex over the 6month interval relative to matched controls, with matched gains in executive inhibitory ability. ${ }^{161}$ In general, longitudinal populationbased studies suggest that greater participation by older adults in social activities may be associated with better cognition. ${ }^{162}$ These findings point to active and meaningful social participation as another target for audiologic rehabilitation designed to promote healthy aging.

\section{IMPLICATIONS FOR AUDIOLOGIC PRACTICE}

As described above, across time and at any given point in time, the health and everyday social functioning of older adults can affect and be affected by age-related declines in hearing and cognition. Consistent with the WHO ICF framework, there is a pressing need to reinvent hearing health care for older adults by adopting a healthy aging approach that emphasizes social participation. The processes for achieving successful aging described in the SOC model could be used as a basis for designing new approaches to rehabilitative audiology and for designing other health-related programs delivered to older adults who have hearing problems. The WHO ICF and SOC model could be applied in programs to prevent, assess, treat, and increase accessibility for older adults who have ARHL.

\section{Prevention}

Fortunately, over the past 20 to 30 years, total disability among Americans 65 years and older has declined by $\sim 25 \%$, possibly in response to rising levels of education and standards of living, better treatment of cardiovascular diseases, reduced rates of smoking, greater availability of assistive devices, and less physically demanding jobs. ${ }^{163}$ Similarly, risk of ARHL decreased throughout the 20th century in North America, possibly in response to lower levels of industrial noise and better control of cardiovascular disease. ${ }^{164}$ Prevention of ARHL may be achieved by addressing risk factors like cardiovascular disease and noise exposure, particularly among young people whose ears may be particularly susceptible to subclinical noise damage. ${ }^{165}$ These findings are inspiring public health researchers to find more ways to slow or prevent age-related health issues, especially cognitive impairment and dementia, and to improve the independence and well-being of older adults. On the one hand, health promotion initiatives that help older adults to maintain good health and active social participation could moderate some of the negative consequences of age-related declines in hearing and cognition. On the other hand, if hearing loss is a modifiable risk factor, especially for dementias and cognitive decline, then sooner and better hearing health care could moderate some of the negative consequences of several age-related health issues.

\section{Assessment}

Audiometric threshold testing has been the cornerstone of traditional audiologic assessment, and hearing aid fitting has been the cornerstone of traditional audiologic rehabilitation. Going beyond the information gathered in a traditional audiologic assessment, information about nonaudiometric factors concerning relevant aspects of an individual's physical, mental, and social health would be needed to plan effective hearing health care in the broader context of healthy aging. Relevant aspects of 
physical health would include background on other sensory modalities (e.g., vision, balance, touch), motor functioning (e.g., dexterity, mobility, falls), and chronic health conditions (e.g., diabetes, cardiovascular disease, hypertension). Relevant aspects of mental health would include background on cognitive functioning (e.g., screening or history of diagnosis of mild cognitive impairment or dementia) and mood (e.g., depression) or other psychological or psychiatric disorders (e.g., anxiety). Audiologists would not typically gather information about physical and mental health issues, and other health professionals, even those diagnosing dementia, seldom gather information about hearing, ${ }^{166}$ even though hearing problems could affect the results of testing. ${ }^{167}$ However, in the context of interprofessional teams, those involved in the care of older adults with multiple health issues could benefit from cooperating and sharing relevant information to ensure that the best quality of health care is provided.

In addition to information about physical and mental health, information about relevant aspects of social functioning would be needed to plan hearing health care designed to promote successful aging. Rehabilitation planning could be greatly enhanced if audiologists had information about the social factors that are most likely to influence an older adult's readiness to seek help, take action, and maintain behavior change to live successfully with hearing loss. These measures would provide insights into the stigma, self-efficacy, social support, social isolation, and social participation issues of the individual with hearing loss. Planning rehabilitation designed to help an older adult achieve a good person-environment fit would also require information about the contextual barriers and facilitators specific to the individual's physical and social communication ecologies. Such information would be used to assess the accessibility needs of the person, in particular communication situations, as well as to characterize the availability of social support and possible concerns regarding third-party disability or caregiver burden. Fortunately, there has been a recent increase in research on applying the principles of health and social psychology in audiologic rehabilitation. ${ }^{168}$

\section{Rehabilitation}

Current rehabilitation options for individuals with ARHL include technologies (e.g., hearing aids, assistive devices, cochlear implants), auditory or communication training, counseling, and group programs. Unfortunately, there is no simple, one-size-fits-all solution for adults with normal cognition, and more specialized interventions for those at various stages of cognitive decline are rarely implemented in typical audiology clinical settings. ${ }^{41,169}$ Some barriers to successful rehabilitation are related to technology that falls short of user expectations or is expensive and/or ergonomically suboptimal. However, there are many other barriers to successful rehabilitation that are primarily related to social factors.

Many older adults delay seeking help for hearing problems and, by the time they first try a hearing aid, they are already affected by multiple physical and cognitive health issues. For decades, hearing health professionals have advocated for fitting hearing aids as soon as possible and certainly while older adults are physically and psychologically able to learn to use the technology. ${ }^{170,171}$ Although some health professionals have questioned the value of hearing rehabilitation for older adults with dementia, it seems that hearing rehabilitation may be of extreme importance in helping these individuals and their family caregivers. ${ }^{43,170,172}$ There is strong evidence that hearing aids and auditory rehabilitation improve communication and hearing-related quality of life. ${ }^{173,174}$ If poorer communication increases risk for social isolation and withdrawal from social participation, which in turn contribute to the link between hearing loss and cognitive decline, then it is possible that improving communication by using hearing aids might weaken the link. In epidemiologic studies, cognitive declines were associated with hearing loss but did not differ between participants who reported using hearing aids and those who did not ${ }^{42,43}$; however, minimal information on hearing aid use was available. High-quality, long-duration randomized controlled trials are needed to determine if older adults with clinically significant cognitive declines benefit as much as peers with normal cognition from current best practices in 
audiologic rehabilitation and if such rehabilitation can slow cognitive declines. ${ }^{14}$

Some older adults are successful in adapting to hearing loss. They identify and accept that they have hearing-related problems; they select the situations and relationships where communication has the most value for them; they optimize by learning new listening skills (e.g., through auditory training and practice), using technologies (e.g., hearing aids and assistive devices), and modifying environments (e.g., by reducing background noise); and they compensate by speech-reading and using communication strategies in conversation (e.g., asking communication partners to speak clearly). But other people have more difficulty making changes to adjust to life as a person with hearing loss. They may not recognize or might deny that they have hearing problems; they might never have their hearing tested; they might avoid social situations out of fear of embarrassment, or take out their frustrations in ways that may damage relationships with friends or family, jeopardize social support, and/or reduce opportunities for interaction. ${ }^{130}$

New approaches may be needed to overcome barriers arising from social factors such as stigma and negative views of aging, poor selfefficacy, lack of social support, and social isolation and/or withdrawal from social interaction. For example, Internet screening may provide an opportunity to reach those who would not come to a clinic for a hearing test. However, the identification of hearing loss by screening may be insufficient to predispose further action; new approaches to increase readiness for hearing rehabilitation will likely be needed to predispose uptake of hearing aids and other changes in behavior to improve hearing-related quality of life. ${ }^{175,176}$ Other new approaches, especially those involving social support, may be needed to reinforce and maintain new behaviors and coping; for example, in one study, harnessing social support by including significant others in rehabilitation classes for individuals with hearing loss resulted in larger reductions in hearing handicap scores for those who attended with a significant other compared with those who attended alone. ${ }^{177}$ The Internet may also provide new opportunities to overcome these barriers; for example, lack of social support predicted the frequency of participation in and subjective benefit from an online selfhelp group for hearing loss. ${ }^{178}$ Finally, new rehabilitative approaches to address the effects of hearing loss on significant others could also help to predispose uptake and reinforce outcomes of audiologic rehabilitation, especially for caregivers of older adults who have hearing loss and clinically significant cognitive declines.

\section{Accessibility}

Reduction of the risk of developing dementias may depend on lifestyle changes and improved treatment or prevention of chronic health conditions, including hearing loss, that confer additional risk. The most important modifiable lifestyle factors include cognitive reserve, physical activity and exercise, dietary factors, alcohol intake, and smoking. The most obvious treatable chronic health conditions include cardiovascular diseases, stroke, midlife hypertension, diabetes, and midlife hypercholesterolemia. ${ }^{179}$ Sadly, many of the potentially modifiable risk factors for dementia, such as socialization, physical activity, and prevention or treatment of chronic health conditions, including hearing loss as a recent addition, are poorly addressed at the population level. Too many people are isolated, sedentary, and do not do anything about hearing impairment. There may be important opportunities to reduce the incidence of cognitive loss if these factors, and others, are addressed in a comprehensive manner in communities, hospitals, and clinics. The current model of health care, however, which is subjugated to the "tyranny of the acute" and divided into professional silos, is not an ideal platform upon which to build a holistic program that aims to prevent chronic illness.

New interprofessional and public health approaches to population health are needed. In particular, such approaches could increase awareness of the importance of hearing health, better integrate hearing health care into the larger health care picture, increase uptake of amplification devices and other forms of audiologic rehabilitation, and mandate public policies and environmental accommodations such as ambient noise controls and access to written information in public 
spaces. At the level of global health policy, within the last decade, the World Health Organization has spearheaded an international "age-friendly cities" agenda to foster environmental and social initiatives for "active aging," including community-level programs to promote the health, security, and the social participation of older adults in society. ${ }^{180} \mathrm{~A}$ challenge to audiologists is to begin to contribute to such initiatives. ${ }^{181}$

\section{CONCLUSION}

Greater attention to improving lifestyle and medical risk factors for cognitive declines is urgently needed across adulthood. Prevention and mitigation of hearing loss may play a significant role in these efforts, in combination with other ways to promote healthy physical, mental, and social aging. Even if dementias cannot be entirely prevented by sooner and better hearing health care, simply delaying the onset of disease would result in significant benefits to individuals and society. It is estimated that a 1-year delay would lead to a $10 \%$ reduction in prevalence by $2050,{ }^{182}$ and there would likely be additional, noncognitive benefits to the health and well-being of older adults. The alternative of doing nothing will almost certainly result in growing strains on families, health care systems, and aging societies. Audiologists have a valuable contribution to make by reinventing hearing care in the context of healthy and successful aging.

\section{REFERENCES}

1. World Health Organization (WHO). International Classification of Functioning, Disability and Health (ICF). Geneva, Switzerland: WHO Press; 2001. Available at: http://www.who.int/ classifications/icf/en/. Accessed April 15, 2015

2. Baltes P, Baltes M. Psychological perspectives on successful aging: the model of selective optimization with compensation. In: Baltes $\mathrm{P}$, Baltes $\mathrm{M}$, eds. Successful Aging: Perspectives for the Behavioral Sciences. New York, NY: Cambridge University Press; 1990:1-34

3. Worrall L, Hickson L. Communication Disability in Aging: From Prevention to Intervention. New York, NY: Delmar Publishers; 2003
4. Stokols D. Establishing and maintaining healthy environments. Toward a social ecology of health promotion. Am Psychol 1992;47(1):6-22

5. Donnellan C, O'Neill D. Baltes' SOC model of successful ageing as a potential framework for stroke rehabilitation. Disabil Rehabil 2014;36(5): 424-429

6. Ouwehand C, de Ridder DT, Bensing JM. A review of successful aging models: proposing proactive coping as an important additional strategy. Clin Psychol Rev 2007;27(8):873-884

7. World Health Organization (WHO). WHO definition of health. Preamble to the Constitution of the World Health Organization as adopted by the International Health Conference, New York, June 19-22 1946; signed on July 22, 1946, by the representatives of 61 States (Official Records of the World Health Organization, no. 2, p. 100) and entered into force on April 7, 1948. Available at: http://www.who.int/about/definition/en/print. html. Accessed October 1, 2014

8. Frankish CJ, Green LW, Ratner PA, Chomik T, Larsen C. Health impact assessment as a tool for population health promotion and public policy: a report submitted to the health promotion development division of Health Canada. Vancouver, BC: University of British Columbia; 1996. Available at: http://catalogue.iugm.qc.ca/GEIDEFile/ healthimpact.PDF?Archive=192469191064. Accessed April 2015

9. Christensen K, Doblhammer G, Rau R, Vaupel JW. Ageing populations: the challenges ahead. Lancet 2009;374(9696):1196-1208

10. Kannisto V, Lauritsen J, Thatcher A, Vaupel J. Reductions in mortality at advanced ages: several decades of evidence from 27 countries. Popul Dev Rev 1994;20:793-810

11. Vaupel JW. Biodemography of human ageing. Nature 2010;464(7288):536-542

12. Suzman R, Haaga J. World demography of aging. In: Longo D, Fauci A, Kasper D, Hauser S, Jameson J, Loscalzo J, eds. Harrison's Principles of Internal Medicine, 18th ed. New York, NY: McGraw-Hill; 2012

13. Mathers CD, Loncar D. Projections of global mortality and burden of disease from 2002 to 2030. PLoS Med 2006;3(11):e442

14. Lustig TA, Olson S. Hearing loss and healthy aging: workshop summary. Washington, DC: The National Academies Press; 2014. Available at: http://www.nap.edu/catalog/18735/hearingloss-and-healthy-aging-workshop-summary. Accessed April 2015

15. Mitchell P, Gopinath B, McMahon CM, et al. Relationship of type 2 diabetes to the prevalence, incidence and progression of age-related hearing loss. Diabet Med 2009;26(5):483-488 
16. Lin HC, Chao PZ, Lee HC. Sudden sensorineural hearing loss increases the risk of stroke: a 5-year follow-up study. Stroke 2008;39(10):2744-2748

17. Kiely KM, Gopinath B, Mitchell P, Luszcz M, Anstey KJ. Cognitive, health, and sociodemographic predictors of longitudinal decline in hearing acuity among older adults. J Gerontol A Biol Sci Med Sci 2012;67(9):997-1003

18. Smith SL, Bennett LW, Wilson RH. Prevalence and characteristics of dual sensory impairment (hearing and vision) in a veteran population. J Rehabil Res Dev 2008;45(4):597-609

19. Erber NP. Use of hearing aids by older people: influence of non-auditory factors (vision, manual dexterity). Int J Audiol 2003;42(Suppl 2):S21-S25

20. Singh G, Pichora-Fuller MK, Hayes D, von Schroeder HP, Carnahan H. The aging hand and the ergonomics of hearing aid controls. Ear Hear 2013;34(1):e1-e13

21. Ferrucci L, Studenski S. Clinical Problems of Aging. In: Longo D, Fauci A, Kasper D, Hauser S, Jameson J, Loscalzo J, eds. Harrison's Principles of Internal Medicine; 18th ed. New York, NY: McGraw-Hill; 2012

22. Huang CQ, Dong BR, Lu ZC, Yue JR, Liu QX. Chronic diseases and risk for depression in old age: a meta-analysis of published literature. Ageing Res Rev 2010;9(2):131-141

23. Viljanen A, Kaprio J, Pyykkö I, Sorri M, Koskenvuo M, Rantanen T. Hearing acuity as a predictor of walking difficulties in older women. J Am Geriatr Soc 2009;57(12):2282-2286

24. Viljanen A, Kaprio J, Pyykkö I, et al. Hearing as a predictor of falls and postural balance in older female twins. J Gerontol A Biol Sci Med Sci 2009; 64(2):312-317

25. Lin FR, Ferrucci L. Hearing loss and falls among older adults in the United States. Arch Intern Med 2012;172(4):369-371

26. Chen DS, Betz J, Yaffe K, et al; Health ABC study. Association of hearing impairment with declines in physical functioning and the risk of disability in older adults. J Gerontol A Biol Sci Med Sci 2015;70(5):654-661

27. Kamil RJ, Li L, Lin FR. Association between hearing impairment and frailty in older adults. J Am Geriatr Soc 2014;62(6):1186-1188

28. Appollonio I, Carabellese C, Magni E, Frattola L, Trabucchi M. Sensory impairments and mortality in an elderly community population: a six-year follow-up study. Age Ageing 1995;24(1):30-36

29. Karpa MJ, Gopinath B, Beath K, et al. Associations between hearing impairment and mortality risk in older persons: the Blue Mountains Hearing Study. Ann Epidemiol 2010;20(6):452-459

30. Feeny D, Huguet N, McFarland BH, Kaplan MS, Orpana H, Eckstrom E. Hearing, mobility, and pain predict mortality: a longitudinal population- based study. J Clin Epidemiol 2012;65(7): 764-777

31. Fisher D, Li CM, Chiu MS, et al. Impairments in hearing and vision impact on mortality in older people: the AGES-Reykjavik Study. Age Ageing 2014;43(1):69-76

32. Genther DJ, Betz J, Pratt S, et al; Health ABC Study. Association of hearing impairment and mortality in older adults. J Gerontol A Biol Sci Med Sci 2015;70(1):85-90

33. van Doorn C, Gruber-Baldini AL, Zimmerman $\mathrm{S}$, et al; Epidemiology of Dementia in Nursing Homes Research Group. Dementia as a risk factor for falls and fall injuries among nursing home residents. J Am Geriatr Soc 2003;51(9): 1213-1218

34. Saravay SM, Kaplowitz M, Kurek J, et al. How do delirium and dementia increase length of stay of elderly general medical inpatients? Psychosomatics 2004;45(3):235-242

35. Erkinjuntti T, Autio L, Wikström J. Dementia in medical wards. J Clin Epidemiol 1988;41(2): 123-126

36. Magaziner J, Simonsick EM, Kashner TM, Hebel JR, Kenzora JE. Predictors of functional recovery one year following hospital discharge for hip fracture: a prospective study. J Gerontol 1990; 45(3):M101-M107

37. Etzioni DA, Liu JH, Maggard MA, Ko CY. The aging population and its impact on the surgery workforce. Ann Surg 2003;238(2):170-177

38. Mick P, Foley DM, Lin FR. Hearing loss is associated with poorer ratings of patient-physician communication and healthcare quality. J Am Geriatr Soc 2014;62(11):2207-2209

39. Foley DM, Frick KD, Lin FR. Association between hearing loss and healthcare expenditures in older adults. J Am Geriatr Soc 2014;62(6): 1188-1189

40. Albers MW, Gilmore GC, Kaye J, et al. At the interface of sensory and motor dysfunctions and Alzheimer's disease. Alzheimers Dement 2015; 11(1):70-98

41. Pichora-Fuller MK, Dupuis K, Reed M, Lemke U. Helping older people with cognitive decline communicate: hearing aids as part of a broader rehabilitation approach. Semin Hear 2013; 34:308-330

42. Lin FR, Metter EJ, O'Brien RJ, Resnick SM, Zonderman AB, Ferrucci L. Hearing loss and incident dementia. Arch Neurol 2011;68(2): 214-220

43. Lin FR, Yaffe K, Xia J, et al; Health ABC Study Group. Hearing loss and cognitive decline in older adults. JAMA Intern Med 2013;173(4):293-299

44. Peters CA, Potter JF, Scholer SG. Hearing impairment as a predictor of cognitive decline in dementia. J Am Geriatr Soc 1988;36(11):981-986 
45. Uhlmann RF, Larson EB, Rees TS, Koepsell TD, Duckert LG. Relationship of hearing impairment to dementia and cognitive dysfunction in older adults. JAMA 1989;261(13):1916-1919

46. Gates GA, Anderson ML, McCurry SM, Feeney MP, Larson EB. Central auditory dysfunction as a harbinger of Alzheimer dementia. Arch Otolaryngol Head Neck Surg 2011;137(4):390-395

47. Gates GA, Beiser A, Rees TS, D'Agostino RB, Wolf PA. Central auditory dysfunction may precede the onset of clinical dementia in people with probable Alzheimer's disease. J Am Geriatr Soc 2002;50(3):482-488

48. Gates GA, Gibbons LE, McCurry SM, Crane PK, Feeney MP, Larson EB. Executive dysfunction and presbycusis in older persons with and without memory loss and dementia. Cogn Behav Neurol 2010;23(4):218-223

49. Idrizbegovic E, Hederstierna C, Dahlquist M, Kämpfe Nordström C, Jelic V, Rosenhall U. Central auditory function in early Alzheimer's disease and in mild cognitive impairment. Age Ageing 2011;40(2):249-254

50. Sinha UK, Hollen KM, Rodriguez R, Miller CA. Auditory system degeneration in Alzheimer's disease. Neurology 1993;43(4):779-785

51. Yamasoba T, Lin FR, Someya S, Kashio A, Sakamoto T, Kondo K. Current concepts in age-related hearing loss: epidemiology and mechanistic pathways. Hear Res 2013;303:30-38

52. Lin FR, Ferrucci L, An Y, et al. Association of hearing impairment with brain volume changes in older adults. Neuroimage 2014;90:84-92

53. Davis MH, Gaskell MG. A complementary systems account of word learning: neural and behavioural evidence. Philos Trans R Soc Lond B Biol Sci 2009;364(1536):3773-3800

54. Peelle J. The hemispheric lateralization of speech processing depends on what "speech" is: a hierarchical perspective. Front Hum Neurosci 2012;6:309. Available at: http://journal.frontiersin.org/article/10.3389/fnhum.2012.00309/full. Accessed April 2015

55. Chételat G, Landeau B, Eustache F, et al. Using voxel-based morphometry to map the structural changes associated with rapid conversion in MCI: a longitudinal MRI study. Neuroimage 2005; 27(4):934-946

56. Kantarci K, Jack CR Jr. Quantitative magnetic resonance techniques as surrogate markers of Alzheimer's disease. NeuroRx 2004;1(2):196-205

57. Mesulam MM. From sensation to cognition. Brain 1998;121(Pt 6):1013-1052

58. Tranel D, Damasio H, Damasio AR. A neural basis for the retrieval of conceptual knowledge. Neuropsychologia 1997;35(10):1319-1327

59. Albert MS, DeKosky ST, Dickson D, et al. The diagnosis of mild cognitive impairment due to
Alzheimer's disease: recommendations from the National Institute on Aging-Alzheimer's Association workgroups on diagnostic guidelines for Alzheimer's disease. Alzheimers Dement 2011; 7(3):270-279

60. McKhann GM, Knopman DS, Chertkow H, et al. The diagnosis of dementia due to Alzheimer's disease: recommendations from the National Institute on Aging-Alzheimer's Association workgroups on diagnostic guidelines for Alzheimer's disease. Alzheimers Dement 2011;7(3):263-269

61. Grady C. The cognitive neuroscience of ageing. Nat Rev Neurosci 2012;13(7):491-505

62. Pichora-Fuller MK, Singh G. Effects of age on auditory and cognitive processing: implications for hearing aid fitting and audiologic rehabilitation. Trends Amplif 2006;10(1):29-59

63. Fratiglioni L, Wang HX. Brain reserve hypothesis in dementia. J Alzheimers Dis 2007;12(1):11-22

64. Nyberg L, Lövdén M, Riklund K, Lindenberger U, Bäckman L. Memory aging and brain maintenance. Trends Cogn Sci 2012;16(5):292-305

65. Scarmeas N, Stern Y. Cognitive reserve and lifestyle. J Clin Exp Neuropsychol 2003;25(5): 625-633

66. Scarmeas N, Luchsinger JA, Schupf N, et al. Physical activity, diet, and risk of Alzheimer disease. JAMA 2009;302(6):627-637

67. Pichora-Fuller MK. Audition and cognition: what audiologists need to know about listening. In: Palmer C, Seewald R, eds. Hearing Care for Adults. Stäfa, Switzerland: Phonak; 2007:71-85

68. Pichora-Fuller MK. Using the brain when the ears are challenged helps healthy older listeners compensate and preserve communication function. In: Hickson L, eds. Hearing Care for Adults. Stäfa, Switzerland: Phonak; 2010:53-65

69. Pichora-Fuller MK. Auditory and cognitive processing in audiologic rehabilitation. In Spitzer J, Montano J, eds. Adult Audiologic Rehabilitation: Advanced Practices, 2nd ed. San Diego, CA: Plural Publishing; 2013:519-536

70. Park DC, Lautenschlager G, Hedden T, Davidson NS, Smith AD, Smith PK. Models of visuospatial and verbal memory across the adult life span. Psychol Aging 2002;17(2):299-320

71. Mattys S, Wiget L. Effects of cognitive load on speech recognition. J Mem Lang 2011;65: 145-160

72. Goy H, Pelletier M, Coletta M, Pichora-Fuller MK. The effects of semantic context and the type and amount of acoustic distortion on lexical decision by younger and older adults. J Speech Lang Hear Res 2013;56(6):1715-1732

73. Schneider BA, Pichora-Fuller MK, Daneman M. The effects of senescent changes in audition and cognition on spoken language comprehension. In: Gordon-Salant S, Frisina R, Popper A, Fay D, 
eds. The Aging Auditory System: Perceptual Characterization and Neural Bases of Presbycusis, Springer Handbook of Auditory Research. Berlin, Germany: Springer; 2010:167-210

74. Cabeza R. Hemispheric asymmetry reduction in older adults: the HAROLD model. Psychol Aging 2002;17(1):85-100

75. Davis SW, Dennis NA, Daselaar SM, Fleck MS, Cabeza R. Que PASA? The posterior-anterior shift in aging. Cereb Cortex 2008;18(5): 1201-1209

76. Olsen RK, Moses SN, Riggs L, Ryan JD. The hippocampus supports multiple cognitive processes through relational binding and comparison. Front Hum Neurosci 2012;6:146

77. Yonelinas AP. The hippocampus supports highresolution binding in the service of perception, working memory and long-term memory. Behav Brain Res 2013;254:34-44

78. Li SC, Naveh-Benjamin M, Lindenberger U. Aging neuromodulation impairs associative binding: a neurocomputational account. Psychol Sci 2005;16(6):445-450

79. Howard MW, Kahana MJ, Wingfield A. Aging and contextual binding: modeling recency and lag recency effects with the temporal context model. Psychon Bull Rev 2006;13(3):439-445

80. Bouton K. Shouting Won't Help: Why I-and 50 Million Other Americans-Can't Hear You. New York, NY: Sarah Crichton Books; 2013

81. Southall K, Gagné J-P, Jennings MB. Stigma: a negative and a positive influence on help-seeking for adults with acquired hearing loss. Int J Audiol 2010;49(11):804-814

82. Levy BR, Slade MD, Kasl SV. Longitudinal benefit of positive self-perceptions of aging on functional health. J Gerontol B Psychol Sci Soc Sci 2002;57(5):409-417

83. Ryan EB, Meredith SD, MacLean MJ, Orange JB. Changing the way we talk with elders: promoting health using the communication enhancement model. Int J Aging Hum Dev 1995;41(2): 89-107

84. Ryan EB, Giles H, Bartolucci G, Henwood K. Psycholinguistic and social psychological components of communication by and with the elderly. Lang Commun 1986;6:1-24

85. Chasteen AL, Schwarz N, Park DC. The activation of aging stereotypes in younger and older adults. J Gerontol B Psychol Sci Soc Sci 2002; 57(6):540-547

86. Cuddy A, Norton M, Fiske S. This old stereotype: the pervasiveness and persistence of the elderly stereotype. J Soc Issues 2005;61:267-285

87. Goffman E. Stigma: Notes on the Management of Spoiled Identity. Englewood Cliffs, NJ: PrenticeHall; 1963
88. Hummert ML, Garstka TA, Shaner JL, Strahm S. Stereotypes of the elderly held by young, middle-aged, and elderly adults. J Gerontol 1994;49(5):240-249

89. Levy B. Stereotype embodiment: a psychosocial approach to aging. Curr Dir Psychol Sci 2009; 18(6):332-336

90. Levy BR, Slade MD, Gill TM. Hearing decline predicted by elders' stereotypes. J Gerontol B Psychol Sci Soc Sci 2006;61(2):82-87

91. Hertzog C, Dunlosky J. Metacognition in later adulthood: spared monitoring can benefit older adults' self-regulation. Curr Dir Psychol Sci 2011; 20(3):167-173

92. Hertzog C, Hultsch DF. Metacognition in adulthood and old age. In: Craik F, Salthouse T, eds. The Handbook of Aging and Cognition. Mahwah, NJ: Lawrence Erlbaum Associates; 2000: 417-466

93. Wallhagen MI. The stigma of hearing loss. Gerontologist 2010;50(1):66-75

94. Hétu R. The stigma attached to hearing impairment. Scand Audiol Suppl 1996;43:12-24

95. Gagné JP, Southall K, Jennings M. The psychological effects of social stigma: applications to people with an acquired hearing loss. In: Montano J, Spitzer J, eds. Advanced Practice in Adult Audiologic Rehabilitation: International Perspective. New York, NY: Plural Publishing; 2009: 63-92

96. Erler SF, Garstecki DC. Hearing loss- and hearing aid-related stigma: perceptions of women with age-normal hearing. Am J Audiol 2002;11(2): 83-91

97. Kang SK, Chasteen AL. The development and validation of the age-based rejection sensitivity questionnaire. Gerontologist 2009;49(3):303-316

98. Bandura A. Self Efficacy: The Exercise of Control. New York, NY: Freeman; 1997

99. van der Bijl JJ, Shortridge-Baggett LM. The theory and measurement of the self-efficacy construct. Sch Inq Nurs Pract 2001;15(3):189-207

100. Plack K, Herpertz S, Petrak F. Behavioral medicine interventions in diabetes. Curr Opin Psychiatry 2010;23(2):131-138

101. Smith SL, West RL. The application of selfefficacy principles to audiologic rehabilitation: a tutorial. Am J Audiol 2006;15(1):46-56

102. Broadhead WE, Gehlbach SH, de Gruy FV, Kaplan BH. The Duke-UNC Functional Social Support Questionnaire. Measurement of social support in family medicine patients. Med Care 1988;26(7):709-723

103. Cohen S. Social relationships and health. Am Psychol 2004;59(8):676-684

104. Broadhead WE, Kaplan BH, James SA, et al. The epidemiologic evidence for a relationship between 
social support and health. Am J Epidemiol 1983; 117(5):521-537

105. Cohen S, Wills TA. Stress, social support, and the buffering hypothesis. Psychol Bull 1985;98(2): 310-357

106. Erber N. Communication Therapy for Adults with Sensory Loss. Melbourne, Australia: Clavis; 1996

107. Carson AJ. "What brings you here today?" The role of self-assessment in help-seeking for agerelated hearing loss J Aging Stud 2005; 19:185-200

108. Lockey K, Jennings MB, Shaw L. Exploring hearing aid use in older women through narratives. Int J Audiol 2010;49(8):542-549

109. Duijvestijn JA, Anteunis LJ, Hoek CJ, Van Den Brink RH, Chenault MN, Manni JJ. Help-seeking behaviour of hearing-impaired persons aged $>$ or $=55$ years; effect of complaints, significant others and hearing aid image. Acta Otolaryngol 2003;123(7):846-850

110. Meyer C, Hickson L, Lovelock K, Lampert M, Khan A. An investigation of factors that influence help-seeking for hearing impairment in older adults. Int J Audiol 2014;53(Suppl 1):S3-S17

111. Mahoney CF, Stephens SD, Cadge BA. Who prompts patients to consult about hearing loss? $\mathrm{Br}$ J Audiol 1996;30(3):153-158

112. van den Brink RH, Wit HP, Kempen GI, van Heuvelen MJ. Attitude and help-seeking for hearing impairment. Br J Audiol 1996;30(5): 313-324

113. Manchaiah VKC, Stephens D, Lunner T. Communication partners' journey through their partner's hearing impairment. Int J Otolaryngol 2013; 2013:707910

114. Brooks DN. The effect of attitude on benefit obtained from hearing aids. Br J Audiol 1989; 23(1):3-11

115. Kochkin S. MarkeTrak VII: Obstacles to adult non-user adoption of hearing aids. Hear J 2007; 60:24-51

116. Hickson L, Meyer C, Lovelock K, Lampert M, Khan A. Factors associated with success with hearing aids in older adults. Int J Audiol 2014; 53(Suppl 1):S18-S27

117. Singh G, Lau S-T, Pichora-Fuller MK. Social support predicts hearing aid satisfaction. Ear Hear, doi: 10.1097/AUD.0000000000000182

118. Frankel B, Turner R. Psychological adjustment in chronic disability: the role of social support in the case of the hearing impaired. Can J Sociol 1983; 8:273-291

119. Hétu R, Lalonde M, Getty L. Psychosocial disadvantages associated with occupational hearing loss as experienced in the family. Audiology 1987; 26:141-152
120. Stephens D, France L, Lormore K. Effects of hearing impairment on the patient's family and friends. Acta Otolaryngol 1995;115(2):165-167

121. Stephens D. Hearing rehabilitation in a psychosocial framework. Scand Audiol Suppl 1996; 43:57-66

122. Heine C, Erber NP, Osborn R, Browning CJ. Communication perceptions of older adults with sensory loss and their communication partners: implications for intervention. Disabil Rehabil 2002;24(7):356-363

123. Kramer SE, Kapteyn TS, Kuik DJ, Deeg DJ. The association of hearing impairment and chronic diseases with psychosocial health status in older age. J Aging Health 2002;14(1):122-137

124. Danermark B, Gellerstedt LC. Psychosocial work environment, hearing impairment and health. Int J Audiol 2004;43(7):383-389

125. Stark P, Hickson L. Outcomes of hearing aid fitting for older people with hearing impairment and their significant others. Int J Audiol 2004; 43(7):390-398

126. Scarinci N, Worrall L, Hickson L. The effect of hearing impairment in older people on the spouse. Int J Audiol 2008;47(3):141-151

127. Scarinci N, Worrall L, Hickson L. The effect of hearing impairment in older people on the spouse: development and psychometric testing of the significant other scale for hearing disability (SOS-HEAR). Int J Audiol 2009;48(10): 671-683

128. Kamil RJ, Lin FR. The effects of hearing impairment in older adults on communication partners: a systematic review. J Am Acad Audiol 2015; 26(2):155-182

129. Wallhagen MI, Strawbridge WJ, Shema SJ, Kaplan GA. Impact of self-assessed hearing loss on a spouse: a longitudinal analysis of couples. J Gerontol B Psychol Sci Soc Sci 2004;59(3): S190-S196

130. Hétu R, Jones L, Getty L. The impact of acquired hearing impairment on intimate relationships: implications for rehabilitation. Audiology 1993; 32(6):363-381

131. Scarinci N, Worrall L, Hickson L. The ICF and third-party disability: its application to spouses of older people with hearing impairment. Disabil Rehabil 2009;31(25):2088-2100

132. George LK, Gwyther LP. Caregiver well-being: a multidimensional examination of family caregivers of demented adults. Gerontologist 1986; 26(3):253-259

133. Dunkin JJ, Anderson-Hanley C. Dementia caregiver burden: a review of the literature and guidelines for assessment and intervention. Neurology 1998;51(1, Suppl 1):S53-S60, discussion S65S67 
134. Zientz J, Rackley A, Chapman SB, et al. Evidence-based practice recommendations for dementia: educating caregivers on Alzheimer's disease and training communication strategies. J Med Speech-Lang Pathol 2007;15(1):53-64

135. Kempler D. Neurocognitive Disorders in Aging. Thousand Oaks, CA: Sage Publications; 2005

136. Savundranayagam MY, Hummert ML, Montgomery RJV. Investigating the effects of communication problems on caregiver burden. J Gerontol B Psychol Sci Soc Sci 2005;60(1):S48-S55

137. Orange JB. Perspectives of family members regarding communication changes. In: Lubinski R, eds. Dementia and Communication. Philadelphia, PA: Mosby; 1991:168-186

138. Ripich DN, Horner J. The neurodegenerative dementias: diagnoses and interventions. ASHA Leader 2004;9:4-5

139. Kinney JM, Stephens MA. Hassles and uplifts of giving care to a family member with dementia. Psychol Aging 1989;4(4):402-408

140. Yaffe K, Fox P, Newcomer R, et al. Patient and caregiver characteristics and nursing home placement in patients with dementia. JAMA 2002; 287(16):2090-2097

141. Carstensen LL, Isaacowitz DM, Charles ST. Taking time seriously. A theory of socioemotional selectivity. Am Psychol 1999;54(3):165-181

142. Tomaka J, Thompson S, Palacios R. The relation of social isolation, loneliness, and social support to disease outcomes among the elderly. J Aging Health 2006;18(3):359-384

143. House JS. Social isolation kills, but how and why? Psychosom Med 2001;63(2):273-274

144. House JS, Robbins C, Metzner HL. The association of social relationships and activities with mortality: prospective evidence from the Tecumseh Community Health Study. Am J Epidemiol 1982;116(1):123-140

145. Green AF, Rebok G, Lyketsos CG. Influence of social network characteristics on cognition and functional status with aging. Int J Geriatr Psychiatry 2008;23(9):972-978

146. Oxman TE, Berkman LF, Kasl S, Freeman DH Jr, Barrett J. Social support and depressive symptoms in the elderly. Am J Epidemiol 1992;135(4): 356-368

147. Strogatz DS, James SA. Social support and hypertension among blacks and whites in a rural, southern community. Am J Epidemiol 1986; 124(6):949-956

148. House JS, Landis KR, Umberson D. Social relationships and health. Science 1988;241(4865): 540-545

149. Pantell M, Rehkopf D, Jutte D, Syme SL, Balmes J, Adler N. Social isolation: a predictor of mortality comparable to traditional clinical risk factors. Am J Public Health 2013;103(11):2056-2062
150. Arlinger S. Negative consequences of uncorrected hearing loss-a review. Int J Audiol 2003;42 (Suppl 2):S17-S20

151. Crews JE, Campbell VA. Vision impairment and hearing loss among community-dwelling older Americans: implications for health and functioning. Am J Public Health 2004;94(5):823-829

152. Mick P, Kawachi I, Lin FR. The association between hearing loss and social isolation in older adults. Otolaryngol Head Neck Surg 2014;150(3): 378-384

153. Seeman TE, Kaplan GA, Knudsen L, Cohen R, Guralnik J. Social network ties and mortality among the elderly in the Alameda County Study. Am J Epidemiol 1987;126(4):714-723

154. Shankar A, Hamer M, McMunn A, Steptoe A. Social isolation and loneliness: relationships with cognitive function during 4 years of follow-up in the English Longitudinal Study of Ageing. Psychosom Med 2013;75(2):161-170

155. Marsiske M, Klumb P, Baltes MM. Everyday activity patterns and sensory functioning in old age. Psychol Aging 1997;12(3):444-457

156. Heyl V, Wahl HW. Managing daily life with agerelated sensory loss: cognitive resources gain in importance. Psychol Aging 2012;27(2):510-521

157. Pham TM, Winblad B, Granholm AC, Mohammed AH. Environmental influences on brain neurotrophins in rats. Pharmacol Biochem Behav 2002;73(1):167-175

158. Neeper SA, Gómez-Pinilla F, Choi J, Cotman CW. Physical activity increases mRNA for brainderived neurotrophic factor and nerve growth factor in rat brain. Brain Res 1996;726(1-2):49-56

159. Lee J, Seroogy KB, Mattson MP. Dietary restriction enhances neurotrophin expression and neurogenesis in the hippocampus of adult mice. J Neurochem 2002;80(3):539-547

160. Fried LP, Carlson MC, McGill S, et al. Experience Corps: a dual trial to promote the health of older adults and children's academic success. Contemp Clin Trials 2013;36(1):1-13

161. Carlson MC, Erickson KI, Kramer AF, et al. Evidence for neurocognitive plasticity in at-risk older adults: the experience corps program. J Gerontol A Biol Sci Med Sci 2009;64(12): 1275-1282

162. Fratiglioni L, Paillard-Borg S, Winblad B. An active and socially integrated lifestyle in late life might protect against dementia. Lancet Neurol 2004;3(6):343-353

163. Schoeni RF, Freedman VA, Martin LG. Why is late-life disability declining? Milbank Q 2008; 86(1):47-89

164. Zhan W, Cruickshanks KJ, Klein BE, et al. Generational differences in the prevalence of hearing impairment in older adults. Am J Epidemiol 2010;171(2):260-266 
165. Kujawa SG, Liberman MC. Acceleration of agerelated hearing loss by early noise exposure: evidence of a misspent youth. J Neurosci 2006;26(7): 2115-2123

166. Jorgensen L, Palmer C, Fischer G. Evaluation of hearing status at the time of dementia diagnosis. Audiol Today 2014;26(1):38-45

167. Dupuis K, Pichora-Fuller MK, Chasteen AL, Marchuk V, Singh G, Smith SL. Effects of hearing and vision impairments on the Montreal Cognitive Assessment. Neuropsychol Dev Cogn B Aging Neuropsychol Cogn 2015;22(4):413-437

168. Fuller P, Kathleen M. Revolutionizing audiologic rehabilitation using approaches from health and social psychology to facilitate adjusting to and living with hearing loss. Hear J. 2015;68(5):6

169. Kricos P. Providing hearing rehabilitation to people with dementia presents unique challenges. Hear J 2009;62(11):39-42

170. Alberti PW. Hearing loss in the elderly: the hidden handicap. Can Fam Physician 1977;23:91-93

171. Davis A, Smith P, Ferguson M, Stephens D, Gianopoulos I. Acceptability, benefit and costs of early screening for hearing disability: a study of potential screening tests and models. Health Technol Assess 2007;11(42):1-294

172. Gates GA, Mills JH. Presbycusis. Lancet 2005; 366(9491):1111-1120

173. Chisolm TH, Johnson CE, Danhauer JL, et al. A systematic review of health-related quality of life and hearing aids: final report of the American Academy of Audiology Task Force on the HealthRelated Quality of Life Benefits of Amplification in Adults. J Am Acad Audiol 2007;18(2):151-183

174. Hawkins DB. Effectiveness of counseling-based adult group aural rehabilitation programs: a sys- tematic review of the evidence. J Am Acad Audiol 2005;16(7):485-493

175. Laplante-Lévesque A, Hickson L, Worrall L. Stages of change in adults with acquired hearing impairment seeking help for the first time: application of the transtheoretical model in audiologic rehabilitation. Ear Hear 2013; 34(4):447-457

176. Laplante-Lévesque A, Brännström KJ, Ingo E, Andersson G, Lunner T. Stages of change in adults who have failed an online hearing screening. Ear Hear 2015;36(1):92-101

177. Preminger JE. Should significant others be encouraged to join adult group audiologic rehabilitation classes? J Am Acad Audiol 2003;14(10): 545-555

178. Cummings J, Sproull L, Kiesler S. Beyond hearing: where real-world and online support meet. Group Dyn 2002;6:78-88

179. Ballard C, Gauthier S, Corbett A, Brayne C, Aarsland D, Jones E. Alzheimer's disease. Lancet 2011;377(9770):1019-1031

180. World Health Organization (WHO). Global agefriendly cities: a guide. Geneva, Switzerland: WHO Press; 2007. ISBN 9789241547307. Available at: http://www.who.int/ageing/age_friendly_cities_guide/en/. Accessed April 15, 2015

181. Fuller P, Kathleen M. A successful aging perspective on the links between hearing and cognition. Perspectives on Hearing and Hearing Disorders: Research and Diagnostics 2014;18:53-59

182. Brookmeyer R, Johnson E, Ziegler-Graham K, Arrighi HM. Forecasting the global burden of Alzheimer's disease. Alzheimers Dement 2007; 3(3):186-191 